The Journal of Community Informatics, 8(1), 2012

ISSN: $1712-4441$

\title{
Getting Turned On: \\ Using ICT training to promote active ageing in New York City
}

\author{
PAULA J. GARDNER, PH.D. \\ Research Scientist, \\ Bridgepoint Collaboratory for Research and Innovation, Bridgepoint Health \\ Assistant Professor, \\ Dalla Lana School of Public Health, University of Toronto \\ pgardner@bridgepointhealth.ca
}

\author{
JULIE NETHERLAND, PH.D. \\ Deputy State Director, New York \\ Drug Policy Alliance \\ New York, NY \\ jnetherland@,drugpolicy.org
}

TOM KAMBER, PH.D.

Executive Director

Older Adults Technology Services, Inc.

Brooklyn, NY

tkamber@oats.org

\section{INTRODUCTION}

As life expectancy continues to rise and in the face of accelerated population aging, preserving and improving the health and well-being of older people has become a significant public health issue of the 21 st century. Creating the environments, policies and programs that support people to live longer and healthier lives as fully engaged members of society has become a priority among governments, academics, and community organizations in many countries including the United States.

Active ageing is the process of optimizing opportunities for health, participation and security in order to enhance quality of life as people age (World Health Organization, 2002, p.12). An active ageing approach recognizes the rights of older people to equality of opportunity and supports their participation in all aspects of community life. The social environment, which includes social support, social connectedness, social participation, and opportunities for lifelong learning, plays a significant role in engagement in life among older adults and is a key determinant of active aging. Seeking ways to enhance the social environments for older adults, communities, service providers and policy makers have recently turned their attention to information and communication technologies (ICT's). 
There is growing consensus that access to essential services and information, maintaining and enhancing social support networks, and opportunities for meaningful social and civic engagement are increasingly compromised by a lack of digital access and literacy. This is a particularly salient issue among older adults as they lag behind other age groups in the adoption and use of computers and the Internet. Technology training programs targeted at seniors have been identified as an effective way to increase computer use and enhance active aging among this population.

\section{The social environment and wellbeing among older populations}

There is a wealth of information to illustrate social connectedness, social participation, and access to information are beneficial to the health and wellbeing of older people. Belonging to a supportive social network makes people feel cared for, loved, esteemed, and valued-all of which have a powerful protective effect on health (World Health Organization, 2003). Social isolation has been shown to be a strong predictor of poor health and linked to cancer and cardiovascular disease (Hawkley, Burleson, Bernston \& Cacioppo, 2003; Hawkey \& Cacioppo, 2003), re-hospitalization (Mistry et al., 2001), depression (Cacioppo, Hughes, Waite, Hawkley \& Thisted, 2006), delayed care-seeking, poor nutrition, and premature mortality (Sederer, 2006).

Access to information and appropriate (e.g., language suitable, designed to accommodate deteriorating vision and hearing) communication systems are predictors of overall health and well-being for older people. A lack of 'good' (useful, accurate, relevant) information impedes access to opportunities, benefits, and services and is a significant barrier to staying engaged in life (Finkelstein, Garcia, Netherland \& Walker, 2008): "Seniors who cannot gain access to information and services because of illiteracy, language barriers, lack of technological knowledge, or a general lack of awareness about the help that is available are at a severe disadvantage when trying to connect with others" (McVeigh, 2005).

Social and civic participation have also been associated with improved physical and mental health, cognition, and emotional well-being among older adults. Older adults who are actively engaged in forms of social participation are less likely to report poor general health or depression (Higgs, Nazaroo \& Hyde, 2004), and social support has been found to alleviate cognitive decline among the elderly population (Lovden, Ghisletta \& Lindenberger, 2005). Civic participation has been positively associated with better physical and mental health in older adults (Kaskie, Imhof, Cavanaugh \& Culp, 2008) including reduced mortality (Musick, Herzog \& House, 1999) and higher levels of well-being (measured by self-rated health, functional dependency and depressive symptomology) (Morrow-Howell, Hinterlong, Rozario \& Tang, 2003).

\section{ICT's and Older Adults in the US}

The recent and growing interest in aging and technology is the result of two major trends - population aging and the digital revolution. It is estimated that by the 2030, there will be 72.1 million older Americans (almost twice their number in 2007), and by 2050, most of the older population (approx 50 million) will be over the age of 75 (Administration on Aging, 2009). The aging society is also an information society, and while the aging population grows, so does the use, development, design, research and sales of information technology (IT). Internet use for example, has risen in the United States from approximately $10 \%$ in 1995 to over $75 \%$ today (Pew, 2009). These two trends are only beginning to coincide however, so that the fastest growing segment of the population is the least likely to use the fastest growing technologies. 
Recent reports illustrate the "age-based digital divide" continues to persist, and although older adults are increasingly using computers and the Internet, today fewer than half $(45 \%)$ of seniors over 65 and $27 \%$ of seniors over 75 are online compared to $78 \%$ of people $50-54,87 \%$ of those $30-34$, and $93 \%$ of 12-17 year olds (Pew, 2009). In addition to lagging behind in adopting these technologies, older adults report having fewer skills and are less confident in their abilities to use computers than younger cohorts (Fox, 2004).

Computer and Internet use among older adults is not a simple matter of "users" and "nonusers"; the adoption and use of IT among this population is a complex process that depends on a variety of factors and occurs across a continuum from "silver surfers" (confident and competent older computer users) (Cody, Dunn, Hoppin \& Wendt, 1999) to "offline seniors" (individuals with no interest or desire in using the technology). A summary of the literature indicates the key factors influencing the use of IT among older adults are both individual (e.g., age, gender, marital status, socioeconomic status, health status, personal attitudes, and perceived benefits of going online (Morrell, Mayhorn \& Benett, 2000; Selwyn, Gorard, Furlong \& Madden, 2003; U.S. Department of Commerce, 2002) and environmental (e.g., access including hardware and software design) (Ownby, 2006).

The impact of computer and Internet use on older adults is overwhelmingly positive; use has been associated with lower levels of loneliness and higher levels of social connectivity, decreased depression, and improved self-esteem and cognitive functioning (Czaja \& Lee, 2007; Straka \& Clark, 2000; White, McConnell, Clipp, Branch, Sloan, Pieper, et al., 2002). In a review of the literature, Hendrix (2000) highlighted several additional outcomes: enhanced self-efficacy; fulfillment of need for meeting people; fun and mental stimulation; enhanced personal control and self-determination; improved education and skills development (e.g., monitor their health status); and increased social interaction.

Training has been found to be particularly important to improving attitudes, knowledge, and confidence, as well as the sustainability of these outcomes among older adults. Teaching methods have been identified as playing a significant role in facilitating older individuals' interaction with and ongoing use of technologies. In particular, a friendly approach (Gagliardi, Mazzarini, Pap, Giuli \& Marcellini, 2008), supportive environment (Hickman, Rogers \& Fisk, 2007) and a relevant curriculum (Segrist, 2004) are important.

In summary, the aging and technology literature highlights the increasing use of digital technologies among older adults, the benefits from use, the complexity of use patterns and behaviors, and the role of training in facilitating the uptake and sustained use of ICT's among older people. The literature additionally makes several "calls" for future work in this area: the need for more training opportunities for older people (Willis, 2006), a more comprehensive understanding of the ways in which older adults utilize computers in their everyday lives and the impact this use has on their health and well-being, and the need for more research to determine how best to train older adults to use new technologies (Czaja \& Shultz, 2006).

The purpose of this study was to address some of these gaps in the literature and assess how participation in a senior's technology training program - Older Adults Technology Service (OATS) - influences the social environments and active ageing of community-dwelling older New Yorkers. The study objectives were: a) To assess the impact of the OATS program on the computer skills and utilization of participants; b) To assess the impact of the OATS program on the health and well-being of participants as measured by changes in: i) social connectedness, ii) access to information, and iii) social and civic participation. 


\section{The Training Program - OATS (Older Adults Technology Services)}

In the typical arena of organizations and agencies providing services to older adults, technology programming often plays a marginal role - a service appended to providers" "core" competencies such as meals provision and case management and provided through volunteer or non-specialist staff. As a consequence, technology programs are often delivered in fragmented, or ad hoc fashion, and falter due to erratic staffing, inappropriate curriculum, technology breakdowns, poor funding, and limited capacity. Comprehensive, community-based technology training programs such as OATS offer a more effective model that is comprised of multiple components - a professionally trained staff, a well-designed and implemented curriculum, the centralization of services including professional development for training instructors, course scheduling, and curriculum development, and experienced, effective leadership.

OATS was founded in 2004 to engage, train, and support senior citizens in using technology to improve their health, finances, and civic and social engagement. Utilizing a community-based approach, OATS has partnered with over 50 non-profit organizations to deliver 10,000 classes and train 6,500 seniors in the city of New York. OATS courses are 10 weeks in length and students meet twice a week for 1.5 hours of in-class training ( 30 hours total). All classes take place at the partner sites in computer labs with Internet access and enough computers for each student. Class size ranges from 10-15 students. All of the classes are taught by trained OATS instructors and follow a curriculum developed by OATS and provided to students in a manual they receive as part of the training.

\section{METHODS}

The study employed a mixed method design and data were collected via telephone surveys, ethnographic fieldwork, and in-depth interviews.

Telephone Surveys: Surveys consisted of open and close-ended questions and were administered in 3 waves - pre-training, immediately post-training and in a 6-month follow-up.

Ethnographic Field-work: Eight site visits were conducted to observe OATS classes. Data was collected using participant observation and informal interviews with participants during the trainings.

In-depth Interviews: In-depth, semi-structured interviews were conducted with staff from each site that had duties or responsibilities directly related to the delivery of OATS programs (e.g., program directors or technology lab coordinators).

The study was conducted across four sites within New York City. Sites were selected that demonstrated interest in supporting an OATS program, served diverse constituencies in different parts of the city, and had the capacity to support basic lab-based classes. The design included at least one new site (i.e., had not offered OATS courses in the past). The community partners provided site-based computer labs for training, collaborated with OATS staff on program implementation, and conducted outreach and recruitment. To be eligible for the study, participants had to be registered in an OATS training course at one of the study sites, over the age of 50, fluent in English, and able to provide consent.

\section{Data Analysis}

Telephone survey data were coded and analyzed using SPSS software. Qualitative data 
(ethnographic field notes and in-depth interviews with service providers) were analyzed using the principles of grounded theory, assessed using established standards of rigor for qualitative research, and analyzed using NVivo. Final analysis integrated qualitative and quantitative data to identify key findings.

\section{RESULTS}

Sixty-six older adults $(n=66)$ completed all three waves of data collection (see Table 1: Characteristics of Study Participants). Forty-six were women and 20 were men, and they ranged in age from 55 to 85 years of age (mean age $=70)^{1}$. In terms of relationship status, $42 \%$ were married, $35 \%$ widowed and $23 \%$ were single or divorced. Almost half $(48 \%)$ of all participants lived alone, most were either white $(52 \%)$ or African American (35\%), and English was the primary language for the majority $(89 \%)$ of participants. The group was overall well educated; most had received at least a high school education and $44 \%$ were college graduates. Three quarters $(76 \%)$ were retired, $10 \%$ were unemployed and seeking work, with the others still working (full or part-time). Level of income was concentrated in the low (45\% lived on $\$ 1000$ $2000 /$ month) and moderate (39\% lived on $\$ 2000-3000 /$ month) range ${ }^{2}$. The majority of participants $(89 \%)$ were living independently and most $(78 \%)$ reported feeling happy with 'good', 'very good' or 'excellent' health.

\section{Table 1: Characteristics of Study Participants}

\begin{tabular}{|lll|}
\hline $\begin{array}{l}\text { Characteristics of Participants }(\mathbf{n}=\mathbf{6 6}) \\
\text { Age } \quad \text { (mean=70 years) }\end{array}$ & \% \\
$\quad 55-64$ & 15 & 23 \\
$\quad 65-74$ & 35 & 53 \\
$\quad 75+$ & 16 & 24 \\
Sex & & \\
$\quad$ Male & 20 & 30 \\
$\quad$ Female & 46 & 70 \\
Relationship status & & \\
$\quad$ married/common law partner & 28 & 42 \\
$\quad$ separated/divorced/single & 15 & 23 \\
$\quad$ widowed & 23 & 35 \\
Living arrangement & & \\
$\quad \begin{array}{l}\text { alone } \\
\quad \text { spouse/partner }\end{array}$ & 32 & 48 \\
\end{tabular}

\footnotetext{
${ }^{1} 81$ participants were originally recruited into the study and completed Survey \#1 (pre-). Of this group 69 completed Survey \#2 (post-) and 66 completed Survey \#3 (6-month follow up). Despite the loss, the study sample size remains strong and when compared with other research, the rate of attrition is not uncommon for this population. Reasons for the loss are as follows: seven participants dropped out of the OATS course due to illness (2), not enough time (3), and new responsibilities caring for an ill spouse (2); two (2) participants did not register for Internet service at home and therefore no longer met study criteria; three (3) participants reported they were "too busy" when contacted to complete the post-course survey; and two (2) participants could not be reached (telephone \# no longer in service) to complete the 6-month follow-up survey. One (1) participant withdrew from the study.

${ }^{2}$ Living on this amount is particularly challenging for older adults living in New York City where rents and the cost of living is much higher than in other places in the country. For a more appropriate measure of poverty for this population see the report produced by the CEO (Center for Economic Opportunity) at http://media.npr.org/assets/news/2009/09/09/poverty_report.pdf.
} 


\begin{tabular}{|c|c|c|}
\hline other family & 4 & 6 \\
\hline roommate & 2 & 3 \\
\hline \multicolumn{3}{|l|}{ Race/Ethnicity } \\
\hline White & 34 & 52 \\
\hline Black/African American & 23 & 35 \\
\hline Latino/Hispanic & 6 & 9 \\
\hline Asian & 2 & 3 \\
\hline \multicolumn{3}{|l|}{ Primary language } \\
\hline English & 59 & 89 \\
\hline Spanish & 3 & 5 \\
\hline Other & 4 & 6 \\
\hline \multicolumn{3}{|l|}{ Education } \\
\hline some high school & 4 & 6 \\
\hline high school graduate & 16 & 24 \\
\hline $\begin{array}{l}\text { business, vocational, or technical } \\
\text { school }\end{array}$ & 4 & 6 \\
\hline some college & 13 & 20 \\
\hline college graduate & 29 & 44 \\
\hline \multicolumn{3}{|l|}{ Employment status } \\
\hline full-time & 5 & 8 \\
\hline part-time & 4 & 6 \\
\hline retired (not seeking employment) & 50 & 76 \\
\hline unemployed/looking for work & 7 & 11 \\
\hline \multicolumn{3}{|l|}{ Monthly income } \\
\hline$<1000$ & 1 & 2 \\
\hline $1000-2000$ & 20 & 45 \\
\hline $2000-3000$ & 17 & 39 \\
\hline $3000-4000$ & 3 & 7 \\
\hline$>5000$ & 3 & 7 \\
\hline \multicolumn{3}{|l|}{ Self-rated health } \\
\hline excellent & 11 & 17 \\
\hline very good & 20 & 30 \\
\hline good & 29 & 44 \\
\hline not so good & 5 & 8 \\
\hline poor & 1 & 2 \\
\hline \multicolumn{3}{|l|}{ Self-rated happiness } \\
\hline happy all the time & 9 & 14 \\
\hline happy most of the time & 42 & 64 \\
\hline content & 14 & 21 \\
\hline unhappy most of the time & 1 & 2 \\
\hline \multicolumn{3}{|l|}{ Level of independence (self-reported) } \\
\hline completely independent & 59 & 89 \\
\hline sometimes get help & 4 & 6 \\
\hline most of the time get help & 1 & 2 \\
\hline
\end{tabular}


The Impact - Increasing confidence and skills and enhancing the social connectedness, access to information and social participation among participants

Findings demonstrate the impact of the OATS computer training program on older adults across various measures: increased and sustained computer use, improved ability and confidence with computer and Internet technology, and a substantial and positive effect on social connectedness, access to information, and social and civic participation.

Confidence, ability, and computer use increased significantly for students who completed the OATS training, and these outcomes were sustained over time. In post-course telephone surveys $94 \%$ of study participants reported an increase (64\% significantly; $30 \%$ somewhat) in their confidence using computers, and $98 \%$ reported an increase (47\% significantly; $27 \%$ somewhat) in their ability to use computers. Prior to the OATS course $51 \%$ of participants reported using a computer regularly (daily or several times per week) whereas immediately after the training 95\% reported regular use. Six months after the OATS training 93\% (63/66) of the participants were still using their computers and $89 \%$ reported they had maintained their skills and were still able to do what they had learned in the course.

Improved skill was also reflected in the ways in which participants used the technology. Over the course of the study the older adults expanded the types of activities they did on their computers and also broadened their explorations on the Internet. For example, prior to taking the OATS course, six participants (of the 66) used the Internet to search for information, whereas in the six-month follow-up, 63 (of 66) were doing so. Almost all participants had a "first-time" story they shared (either in post- or follow-up surveys) which illustrated new skills, knowledge, and their improved prowess with the technology:

"I'm the recording secretary at our Temple. In the past I wrote it out and gave it to everyone. Now I type it into my computer, save it to a file with a date... It's a very big thing for me." (74-year-old woman)

“I don't get help, now I'm the computer person." (58-year old-woman)

"I use Pandora now to listen to music. And I installed some new games to play." (72-year-old man)

"I went online and got a parking sticker for a State Park, then I used MapQuest to get directions to the Park." (75-year-old man)

Progress in individual ability and skills were also demonstrated by changes in computerrelated vocabulary among participants; there were a lot fewer "whatchamacallits" and "hoosits" in the post-course surveys, and instead people made reference to the "usb cable", "address bar", and "search engine". For those who have grown up in the digital age, it is easy to forget how much of our language is technological and how we assume fluency in the language. As one participant reminds us, this assumption makes life challenging and frustrating for those who are unable to, "speak the language":

"The first line on anything is 'take the usb cable and plug it into the...' What hole? What's a usb?" (76-year-old woman)

Analysis revealed that the OATS training course also had a positive impact on social 
connectedness, access to information, and social and civic participation among study participants. For example, 64\% of participants reported that the amount of time they spent communicating with friends and family increased as a result of the OATS training. Prior to OATS training $1.8 \%$ of participants used email as their primary and $24.6 \%$ as their secondary form of communication with family whereas after the training, 8.8\% reported email as their primary and $49.1 \%$ as their secondary form of communication with family. Email was not seen as a replacement for the telephone by study participants, but as another tool for staying connected and one that, in certain situations, was seen to be more effective than the telephone:

"I use email now for my kids and grandkids cause they'll 'catch it'-cause that's what they're into. They get back to me faster than if I leave a message on their telephone." (65-year-old female)

"Email is good for me-I have trouble hearing on the phone." (66-year-old male)

It was common for study participants to describe feeling more connected to their families in ways they were unable to before their training:

"I'm part of the family again, I get family emails, I'm part of the gang." (73-yearold female)

Email communication was used by participants to stay in touch with friends and relatives both near (in New York City) and far. It was seen as particularly important for older immigrants providing a new way to stay connected to family and friends who lived in other countries:

"I have family in the Philippines-now I feel very connected to them." (74-yearold female)

Email was also seen by many to be very important for staying in touch with grandchildren:

"My main support person in my life is leaving-my grandson is going to college. This is my main reason for taking OATS. I need to be able to stay in touch with him." (78-year-old female)

The training also enhanced participant's ability to access information. In the post-course survey for example, $89 \%$ reported that their ability to access information increased as a result of the training (56\% significantly increased; 33\% somewhat increased).

"Before it was like I was in the best library in the world but all the books were laying all over the floor and not organized-now they are on the shelves and I can find what I need." (60-year-old male)

Analysis also illustrated a significant increase in the frequency with which the group used the Internet as a tool for gathering information (see Figure 1: Frequency of using computer to access information). Prior to taking the OATS course $22 \%$ of participants said they used the Internet regularly (often $12.5 \%$, very often, $9.4 \%$ ) to get information compared with $78 \%$ who reported regular use (often $51.6 \%$, very often $26.6 \%$ ) in the six-month follow up survey. Indeed, prior to the OATS course, $44 \%$ of participants (28) said they never used a computer to access information whereas six months later $100 \%$ of participants who were still using their computers $(63 / 66)$ reported they did so. 


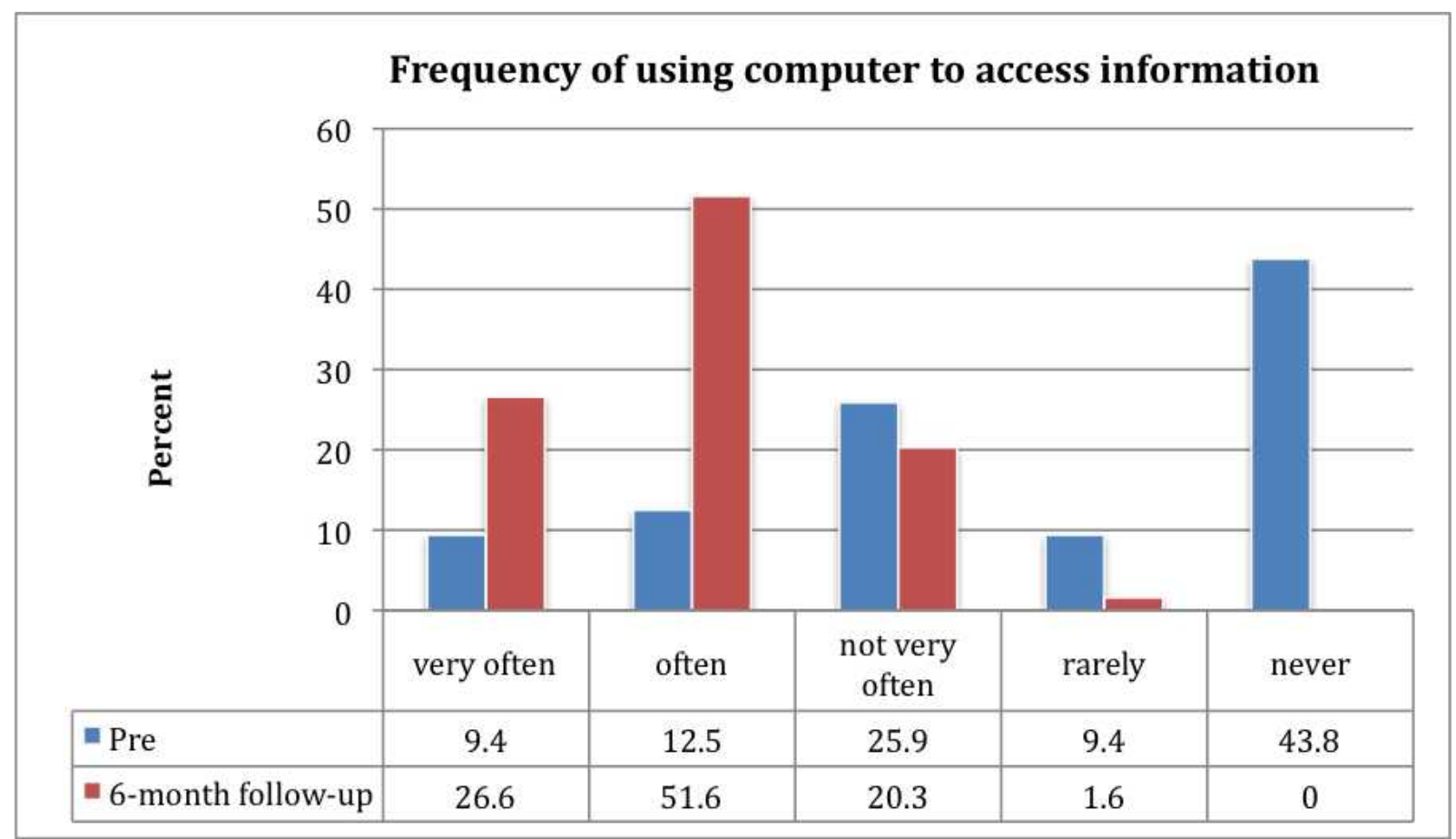

Figure 1: Frequency of using computer to access information

As a result of their improved online abilities and increased use of the Internet as a source of information, participants described feeling better informed. When asked if they ever felt like they were missing information, 47\% answered "yes" in pre-OATS surveys, compared with 14\% in the 6-month follow-up surveys. The many students who added comments such as "not anymore" when answering "no" to this question further illustrated this change.

The computer training program and the concomitant increase in computer literacy also had a positive impact on participants' social and civic engagement. Forty-four percent (44\%) felt their awareness of social activities had increased as a result of the OATS training and 24\% reported that the number of social activities they participated in had increased.

"My social life is a lot better since learning the computer. I can find cheap hotels, book trips, find dance classes!” (69-year-old female)

As their skills and confidence improved, participants increasingly used their computers to learn about cultural events and activities available in the City (49\% reported doing so in followup surveys). Follow-up survey data illustrate other ways participants used their computers to increase their awareness and participation in online and offline social and civic activities (see Figure 2: Computer use for social and civic participation). 


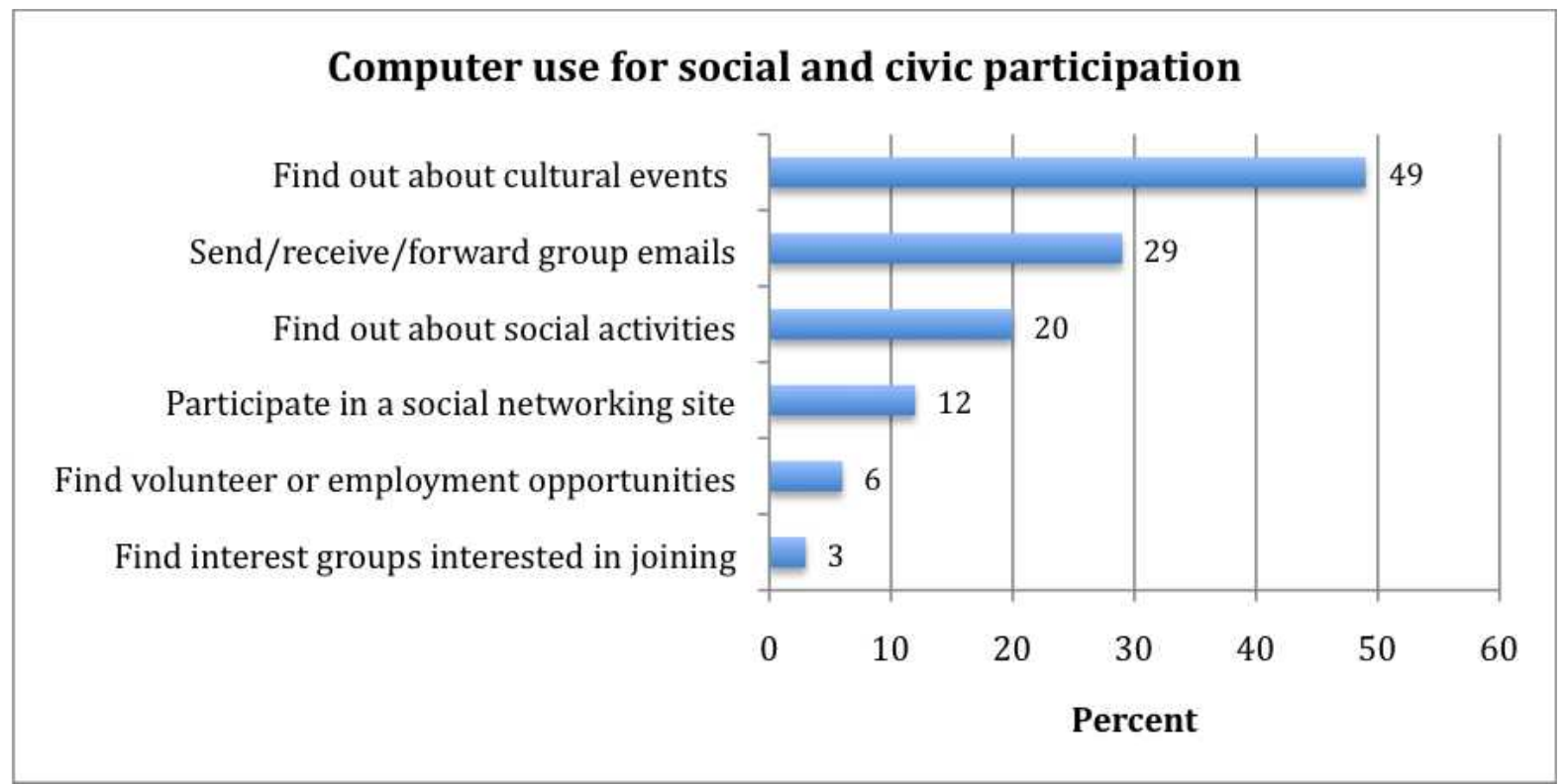

\section{Figure 2: Computer use for social and civic participation}

One of the most interesting ways improved civic engagement was demonstrated related to the election campaign and presidency of US President Obama. Obama and his team used digital media strategies such as Facebook, Twitter and online organizing techniques extensively in his presidential campaign. Additionally, there has been a substantial growth in digital media sources that are not just supplementary to traditional media, but replace it. As such, for the many (like many of the study participants) who are interested in following Obama's political (and personal) life, access and ability with digital technologies is a must. Many participants reported that keeping track of Obama and following his presidency was a key motivator for their computer use and a focus of their online searching. These participants were very pleased with the kinds of information they could access from the Internet in this regard, as well as the speed and interactive nature of the information:

"You can watch him give a speech, see his schedule and then see a slide show of photos of him and his family living in the White House!" (73-year-old female)

"I like to follow the president now, how could I do that without it [the computer]?" (61-year-old male)

The social lives of study participants were also affected directly by physically attending the in-person classes. Students spent a considerable amount of time in the classes (twice a week for $1.5 \mathrm{hrs}$ ) and described the classes as "fun" and a good place to meet people and make new friends. In post-course and follow-up surveys many participants said they missed the social interaction with students and the instructor and some experienced a significant decrease in their level of social activity when the class ended.

In summary, participation in the community-based OATS training program facilitated knowledgeable, confident, and enthusiastic online computer users. The trainings promoted the successful adoption and sustained use of ICT's and served to enhance social connectedness, increase access to information, and facilitate opportunities for social and civic participation among study participants. 


\section{DISCUSSION}

\section{ICT training for older adults: Building, maintaining and restoring community in New York City}

In the United States, the ability to use information technology is now assumed by most to be a prerequisite to living in the "information age". Indeed, without the skills and knowledge to effectively use computers and access the Internet, it is becoming increasingly difficult to negotiate the myriad of resources and information required (and available) to be fully engaged members of society. As ICT's become essential tools for daily living there is concern that those who use them less - the majority of whom are considered the most vulnerable in our society (e.g., "oldest old", immigrants, the poor and those with limited education) $)^{3}$ - may become increasingly disenfranchised and disadvantaged.

The digital divide is not only/simply about age, but also reflects existing political and economic divides (Gomez \& Fernando Baron-Porras, 2011; J. CI). In the United States for example, where individualism, independence and productivity are the cornerstone of American social and political values, those who are very old, poor, and/or disabled are much less likely to use ICT's which, in turn, makes them much more likely to be excluded from society.

ICT's have the potential to contribute to individual and community empowerment and capacity building and can be an effective antidote to social exclusion among older adults. Results from this study suggest comprehensive, community-based ICT training programs (such as OATS), can support the ongoing engagement and re-engagement of older adults within society by building, maintaining and restoring their place within their various communities (including city, neighborhood, family, and communities of choice based on interest or identity).

\section{Building new communities:}

The OATS training course and enhanced ICT abilities provided participants with opportunities to establish new community ties. First, attending the classes themselves created a new learning community among the students and instructor. Feeling connected to this new community was felt by almost all participants during the course, and continued for many after the course was completed (either through online, in-person or telephone communication). Secondly, having the skills needed to negotiate the Internet meant study participants had access to a wealth of information (some of which was new because it was only available online) about their communities of interest. This allowed them to find new opportunities (events, activities, etc) in the City, to get involved, and meet others who shared their interests. For example a student interested in exercise searched the Internet and located a walking group in her area that she joined that she hadn't known existed. Becoming online computer users also provided opportunities to become engaged in the vast array of online communities. Initially most students were nervous about social networking sites however as their confidence and abilities increased over time so did their interest in exploring these communities. Indeed, by the end of the course many participants had joined Senior-planet (online site hosted by OATS), and several others had become members of other social networking sites including Facebook. Building new community ties and the friendships that develop within them are very important to participants who

\footnotetext{
${ }^{3}$ The digital divide exists within the older adult population generally, however it is most pronounced among certain subgroups that are already considered some of the most vulnerable in our society - the "oldest old", immigrants and minority populations, the poor and those with limited education.
} 
described that many of their "old" friends had died and that it was increasingly difficult to make new friends in their later years.

\section{Maintaining community:}

The use of ICT's also enabled these older adults to maintain important social networks that were at risk of being lost. As siblings, partners and good friends die, older adults experience a shrinking community of family and friends. Important social networks can further deteriorate when friends and/or family members relocate. Participants reported feeling very upset about losing the in-person interaction with family members and close friends who had moved away and were anxious about losing touch with them. Their increased use and ability with computers and the Internet provided a new and important communication tool (in particular Email) that helped them to maintain these relationships. Wanting to stay connected to grandchildren who had moved away to college was a key motivator for learning ICT's among this group of older adults and they were thrilled (and grateful) with their ability to do so using their new skills.

\section{Restoring community:}

Prior to the computer training many of the study participants reported that they felt 'lost' and 'left out' frequently during family visits as the conversation almost always included reference to technology (e.g., new 'gadgets'; technological vocabulary; interesting websites). Their feelings of being isolated from these exchanges changed dramatically however with their new ICT understanding and ability. During the post-course interviews it was common for study participants to describe feeling much more engaged and (re)connected with their families: "I'm part of the family again, I get family emails, I'm part of the gang" (73-year-old female). For the immigrant participants the training provided them with the skills they needed to not only maintain but also restore community ties with their homeland. Finding and re-communicating with "lost" family and friends as well as the ability to read local news from their home countries, cities, and even neighborhoods where there were born was extremely important (and very exciting) to these individuals.

The ability of older adults to remain engaged, respected, and contributing members of their communities is essential their overall health and well being. Feeling part of a community whether it is family, neighborhood, or a community founded on identity or interest - promotes good mental health and overall well being, and is essential to active aging. Comprehensive and well-designed and implemented community-based technology training programs such as OATS enable older adults to remain engaged community members. Making ICT's accessible, useable and useful to this population is an effective strategy for mitigating the challenges of population aging while enhancing the quality of life of older adults and the communities within which they live, work and play. 


\section{References}

Administration on Aging (AOA) (2009). A Profile of Older Americans, 2009. Retrieved January 10, 2011 from http://www.aoa.gov/aoaroot/aging_statistics/Profile/index.aspx.

Cacioppo, J. T., Hughes, M. E., Waite, L. J., Hawkley, L. C., \& Thisted, R. A. (2006). Loneliness as a specific risk factor for depressive symptoms: Cross-sectional and longitudinal analyses. Psychology and Aging, 21(1), 140-151.

Cody, M. J., Dunn, D., Hoppin, S., \& Wendt, P. (1999). Silver surfers: Training and evaluating internet use among older adult learners. Communication Education, 48(4), 269-286

Czaja, S. J., \& Lee, C. C. (2007). The impact of aging on access to technology. Universal Access in the Information Society, 5(4), 341-349.

Czaja, S. J., \& Schulz, R. (2006). Innovations in technology and aging introduction. Generations, 30(2), 6-8.

Finkelstein, R., Garcia, A., Netherland, J., \& Walker, J. (2008). Toward an age-friendly New York City: A findings report. New York, NY: New York Academy of Medicine. Retrieved January 10, 2011 from http://www.nyam.org/agefriendlynyc/tools-and-resources.

Fox, S. (2004). Older Americans and the Internet. Pew Internet and American Life Project. Retrieved online January 15, 2011 from http://www.pewinternet.org/Reports/2004/OlderAmericans-and-the-Internet.aspx.

Gagliardi, C., Mazzarini, G., Papa, R., Giuli, C., \& Marcellini, F. (2008). Designing a learning program to link old and disabled people to computers. Educational Gerontology, 34(1), 15.

Gomez, R. \& Fernando Baron-Porras, L. (2010). Public access to the Internet and social change: An experience in Columbia, between silence and hope. The Journal of Community Informatics, 6(3).

Hawkley, L. C., \& Cacioppo, J. T. (2003). Loneliness and pathways to disease. Brain Behavior and Immunity, 17, S98-S105.

Hawkley, L. C., Burleson, M. H., Berntson, G. G., \& Cacioppo, J. T. (2003). Loneliness in everyday life: Cardiovascular activity, psychosocial context, and health behaviors. Journal of Personality and Social Psychology, 85(1), 105-120.

Hendrix, C. C. (2000). Computer use among elderly people. Computers in Nursing, 18(2), 62-8; quiz 69-71.

Hickman, J. M., Rogers, W. A., \& Fisk, A. D. (2007). Training older adults to use new technology. Journals of Gerontology Series B: Psychological Sciences and Social Sciences, 62(Special Issue 1), 77. 
Higgs, P., Nazaroo, J., \& Hyde, M. (2004). The relationship between health and social participation: Results from the English Longitudinal Study of Aging (ELSA). The Gerontologist, 44, 288.

Kaskie, B., Imhof, S., Cavanaugh, J., \& Culp, K. (2008). Civic engagement as a retirement role for aging Americans. Gerontologist, 48(3), 368-377.

Lovden, M., Ghisletta, P., \& Lindenberger, U. (2005). Social participation attenuates decline in perceptual speed in old and very old age. Psychology and Aging, 20(3), 423-434.

McVeigh, K. (November 22, 2005). Seniors at risk for social isolation, New York City, 20022003. New York, NY: Department of Health and Mental Hygiene.

Mistry, R., Rosansky, J., McGuire, J., McDermott, C., \& Jarvik, L. (2001). Social isolation predicts re-hospitalization in a group of older American veterans enrolled in the UPBEAT Program. International Journal of Geriatric Psychiatry, 16(10), 950-959.

Morrell, R. W., Mayhorn, C. B., \& Bennett, J. (2000). A survey of world wide web use in middle-aged and older adults. Human Factors, 42(2), 175.

Morrow-Howell, N., Hinterlong, J., Rozario, P., \& Tang, F. (2003). Effects of Volunteering on the well-being of older adults. Journals of Gerontology Series B: Psychological Sciences and Social Sciences, 58(3), 137-145.

Musick, M. A., Herzog, A. R., \& House, J. S. (1999). Volunteering and mortality among older adults: Findings from a national sample. Journals of Gerontology Series B-Psychological Sciences and Social Sciences, 54(3), S173-S180.

Ownby, R. L. (2006). Making the Internet a friendlier place for older people. Generations, 30(2), 58-60.

PEW Internet Project. (2009). Generations Online, 2009. Retrieved January 12, 2011 from http://www.pewinternet.org/Reports/2009/Generations-Online-in-2009.aspx

Sederer, L.I. (2006). Depression, Social Isolation and the Urban Elderly: Conference on Geriatric Mental Health. New York City Department of Health and Mental Hygiene. Retrieved on January 14, 2011 from http://www.nyc.gov/html/doh/downloads/ppt/dmh/dmh-depressionsederer.ppt

Segrist, K. A. (2004). A computer training program for older adults. Activities, Adaptation \& Aging, 28(4), 13-26.

Selwyn, N., Gorard, S., Furlong, J., \& Madden, L. (2003). Older adults' use of information and communications technology in everyday life. Ageing \& Society, 23(05), 561-582.

Straka, S., \& Clark, F. (2000). Connections: Internet access for frail older seniors to improve 
their psychosocial well-being. Montreal, Quebec: The McGill Centre for Studies in Aging. Retrieved January 20, 2011 from http://aging.mcgill.ca/connections.htm

U.S. Department of Commerce. (2002). A nation online: How Americans are expanding their use of the Internet. Economics and Statistics Administration National Telecommunications and Information Administration. Retrieved January 16, 2011 from http://www.ntia.doc.gov/ntiahome/dn/anationonline2.pdf

White, H., McConnell, E., Clipp, E., Branch, L. G., Sloane, R., Pieper, C., et al. (2002). A randomized controlled trial of the psychosocial impact of providing internet training and access to older adults. Aging \& Mental Health, 6(3), 213-221.

Willis, S. L. (2006). Technology and learning in current and future generations of elders. Generations, 30(2), 44-48.

World Health Organisation. (2002). Active ageing: A policy framework. Geneva: World Health Organization. Retrieved January 16, 2011 from http://www.who.int/ageing/publications/active/en

World Health Organization (2003). Social determinants of health: The solid facts. (2nd Ed.). Geneva: World Health Organization. Retrieved January 16, 2011 from http://www.euro.who.int/en/what-we-publish/abstracts/social-determinants-of-health.-the$\underline{\text { solid-fact }}$ 
To cite this article:

Gardner, P., Kamber, T., \& Netherland, J. (2012). Getting turned on: Using ICT training to promote active ageing in New York City. The Journal of Community Informatics, 8(1). Retrieved from http://ci-journal.net/index.php/ciej/article/view/809/907

All material submitted to the Journal of Community Informatics is protected by and subject to the Creative Commons Public License "Attribution-NonCommercial-ShareAlike 2.5". Subject to the following conditions, all material submitted to the Journal of Community Informatics may be freely copied, distributed, or displayed, or modified:

Attribution. You must attribute the work in the manner specified by the author or licensor.

Noncommercial. You may not use this work for commercial purposes.

Share Alike. If you alter, transform, or build upon this work, you may distribute the resulting work only under a license identical to this one.

See the Creative Commons Attribution-NonCommercial-ShareAlike 2.5 License for complete details. 